\title{
The Analgesic Metamizole (Dipyrone) and Its Related Products Antipyrine, 4-Aminoantipyrine and 4-Methylaminoantipyrine. Part 1: Mass Spectrometric and Electrochemical Detection
}

\author{
Achim Habekost* \\ Department of Chemistry, University of Ludwigsburg, Ludwigsburg, Germany \\ *Corresponding author: habekost@ph-ludwigsburg.de
}

\begin{abstract}
A drastic increase in the consumption of pharmaceuticals has resulted in a high load of pharmaceuticals in wastewater. Many pharmaceuticals are non-biodegradable and are resistant to conventional wastewater treatments. For this reason there is an obvious need to first detect these substances and, second, to detoxify them. Metamizole is a typical representative of an analgesic non-steroidal. In this first part, a rapid, sensitive, and inexpensive detection method with different commercial screen-printed electrodes (SPEs) were used to quantitatively detect metamizole. (Spectro-)Electrochemical methods such as cyclic voltammetry (CV), electrogenerated chemiluminescence (ECL), and amperometry (AM) are discussed in detail and the sensitivities of the electrochemical methods are compared to the sensitivity of conventional gas chromatography-mass spectrometry detection (GC-MSD). The limit of detection (LOD) is $1 \mu \mathrm{mol} / \mathrm{L}$ for GCMS and 5 to $50 \mu \mathrm{mol} / \mathrm{L}$ for electrochemical detection depending on the method used.
\end{abstract}

Keywords: metamizole (dipyrone), 4-aminoantipyrine, 4-methylaminoantipyrine, electrochemical detection, mass spectrometric detection

Cite This Article: Achim Habekost, "The Analgesic Metamizole (Dipyrone) and Its Related Products Antipyrine, 4-Aminoantipyrine and 4-Methylaminoantipyrine. Part 1: Mass Spectrometric and Electrochemical Detection." World Journal of Chemical Education, vol. 6, no. 3 (2018): 134-144. doi: 10.12691/wjce-6-3-6.

\section{Introduction}

Pharmaceuticals, personal care products and endocrine active substances have been recognised as being important topics in environmental chemistry [1]. Several thousand active ingredients are used for drugs in an even greater number of products. In Germany alone, about 50,000 drugs are registered for human use with 2700 accounting for $90 \%$ of the total consumption. These drugs contain about 900 different active substances. In addition, in Europe, half of the antibiotics used are for veterinary purposes [1]. The drastic increase in the consumption of pharmaceuticals has resulted in a high load of pharmaceuticals in wastewater. Many pharmaceuticals are non-biodegradable and are resistant to conventional wastewater treatments (i.e. biological degradation).

Feldmann et al. [2] detected a considerable amount of pharmaceutical residues in the aquatic environment. These authors distinguish between two sources of discharge: (1) wastewater from private households and (2) medical facility effluents, e.g., from hospitals. The pharmaceuticals from these different sources differ in occurrence and composition.

A wide range of concentrations of hazardous substances is present in hospital effluent. Hospital wastewater consists of disinfectants, sterilizers, radioactive markers, detergents and organic compounds such as alcohols, acetone and phenols. The occurrence of pharmaceuticals in hospital effluent has been intensively investigated by Thomas [3], Gomez [4], Kümmerer [1] and Verlicchi et al. [5].

As an example, Verlicchi et al. [5] analysed more than 50 inflammatory substances, antibiotics, barbiturates, beta-blockers, diuretics, psychiatric drugs and cytostatics in the effluent of two hospitals in the north of Italy.

Kümmerer [1] distinguished between different uses of the substances. Of the substances used in veterinary medicine and in farming for improving nutrient uptake, antibiotics, such as tetracycline, and hormone products are the most important chemical group. Other important substances are cytostatic agents, which carry a high risk potential for the environment because these substances are highly toxic to healthy people.

In this paper, we investigated metamizole, assuming it to be a significant representative of diversely used pharmaceuticals. Metamizole (dipyrone or Novalgin ${ }^{\circledR}$ ) is a non-opioid analgesic with a high potential. The analgesic effect is attributed to the inhibition of cyclooxygenase $(\mathrm{COX})$ and the disabling of prostaglandin synthesis [6]. Because metamizole can cause an allergic response and rhinoconjunctivitis (a disease of the nasal mucosa), as well as agranulocytosis (a reduction of granulocytes) [6], metamizole has been withdrawn from the market in some countries. However, metamizole is still widely available and used in countries such as Germany, Spain and France [2]. 
Metamizole is a prodrug, which hydrolyses to 4-methylaminoantipyrine and then into many other metabolites. These metabolites are known to be non-biodegradable [7]. Gyenge-Szabo et al. [8] determined the main metabolites to be 4-aminoantipyrine, 4-acetylaminoantipyrine, 4-formylaminoantipyrine and 4-methylaminoantipyrine. These were found in communal wastewater that was collected; after reversed-phase solid phase extraction, the probes were analysed with a Micromass Q-TOF instrument. The limit of detection (LOD) was in the microgram per litre range. Zhang et al. [9] investigated 4-methylaminoantipyrine, 4-formylaminoantipyrine and 4-acetylaminoantipyrine in goat tissues using liquid chromatography-tandem mass spectrometry and found values ranging from 0.4 to $6 \mu \mathrm{g} / \mathrm{kg}$.

In environmental chemistry, there is an obvious need to first detect these substances and then to detoxify them. In this paper, several analytical procedures will be discussed and compared regarding the speed of the tests and the LOD. The elaborate and expensive gas chromatography-mass spectrometry (GC-MS) technique, operating in different modes (scan and selected ion monitoring SIM mode), is compared to a rapid, sensitive and inexpensive electrochemical detection method employing different commercial screen-printed electrodes (SPEs) (i.e. single-walled carbon nanotubes SWCNT, graphite and $\mathrm{Au}$ SPE). The electrochemical detection technique can operate on site and can identify contaminated probes very quickly. Spectroelectrochemical methods such as cyclic voltammetry (CV), electrogenerated chemiluminescence (ECL) and amperometry (AM) are discussed in detail and the sensitivities of these methods are compared to the sensitivity of the different modes of GC-MS detection.

\section{Pedagogical Objectives}

In general, students are interested in securing a healthy earth for future generations. Chemistry students have a unique opportunity to work in the field of green chemistry. Following Anatas and Warner [10], Hjeresen et al. [11] listed twelve principles of green chemistry. In our context, three of these principles that are considered the most important are the following: Prevention: It is better to prevent waste than to treat or clean up waste after it has been created. Design for Degradation: Chemical products should be designed so that at the end of their function they break down into innocuous degradation products and do not persist in the environment. Real-Time Analysis for Pollution Prevention: Analytical methodologies need to be developed further to allow for real-time, in-process monitoring and control prior to the formation of hazardous substances.

Hill et al. [12] give a review of sustainable-oriented chemistry education. They emphasized that sustainable development is essential to sustainable natural resource management. With regard to the UN declaration of 2011 as the International Year of Chemistry, the authors established a roadmap for the future of chemistry and chemistry education. Among other topics, the preservation of water quality is one of the main factors in sustainable development. Some of the principles of green chemistry, i.e. safety and quality control and the reduction of the toxicity of the harmful substances, are also important topics in this declaration. Therefore, chemical education plays a pivotal role in revealing how water security is important for the survival of humanity.

It is generally agreed that analytical chemistry courses are an important component of college and school curricula. In first-year courses, typical preparatory chemistry combined with qualitative and quantitative courses dominate the laboratory work. In advanced courses, electrochemical and photometric investigations are conducted. Final analytical courses intend to encourage interest in analytical chemistry. Some topics handle complex apparatus, such as mass spectrometers and NMR spectrometers, AAS, HPLC, potentiostats, etc. This is done by solving chemical problems, e.g., determining the LOD of the different analytical methods.

In a chemical sense, the analytical chemistry of harmful and threatening substances and their detoxification is a great challenge for chemical education both in university and in (high) school. However, the elaborate apparatus and the analytical methods used suggest that the topic is suitable for university-level lessons [13].

We would like to summarise the didactic reasons for presenting the unusual method electrogenerated chemiluminescence (ECL) to an audience of chemistry students. ECL is not only an aesthetic technique but also a relatively new and sound electrochemical method. The goals of using ECL are the following:

to demonstrate that ECL correlates to CV predictions,

- to investigate electrochemical instruments (potentiostat, light detection), and

- to use ECL in analytical techniques - in particular, to investigate pharmaceutical substances such as metamizole. We refer the reader to a review on this subject [14].

\section{Experimental}

Chemicals and materials: Ttris(2,2'-bipyridyl)ruthenium (II) chloride (Sigma, 34967), DL-proline (Sigma-Aldrich, 171824), buffer (boric acid / sodium hydroxide mixture, pH 10) (Roth, Germany), metamizole (Caelo, Hilden, Germany, 2486).

$U V$-VIS: photometer (Perkin Elmer, Lambda XLS+)

GC-MS: GC: Hewlett-Packard 6890 with an HP-5 column. Temperature profile: start temperature $100^{\circ} \mathrm{C}$, $2 \mathrm{~min}$ isotherm temperature ramp $15^{\circ} \mathrm{C} / \mathrm{min}$; end temperature: $270^{\circ} \mathrm{C}, 2 \mathrm{~min}$ isotherm. MS: Hewlett-Packard 5973; injection: $1 \mu \mathrm{L}$.

Electrochemistry: potentiostat ( $\mu$ Stat 400, DropSens), screen-printed electrodes (SPEs) (DRP-220 Au-AT, Au as the working electrode, $\mathrm{Au}$ as the counter electrode, $\mathrm{Ag}$ as the pseudoreference electrode; DRP 110: graphite as the working electrode; DRP-SWCNT; DRP-CNT-Au: carbon nanotubes decorated with gold nanoparticles). All SPEs were from DropSens.

Amperometry: HPLC pump (Knauer HPLC pump 64), Rheodyn injection valve, $10 \mu \mathrm{L}$ loop, electrochemical HPLC cell (DRP HPLCELL, DropSens).

Electrogenerated chemiluminescence: ECLSTAT (potentiostat + ECL-cell (DropSens)). 


\section{Results}

\subsection{Photometric Characterisation of} Antipyrine, 4-aminoantipyrine, 4-methylaminoantipyrine and Metamizole

The UV-VIS spectra of antipyrine, 4-aminoantipyrine, 4-methylaminoantipyrine and metamizole are very similar.
According to Bacil et al. [15], the spectra represent three $\pi \rightarrow \pi^{*}$ transitions, which are common to all phenazones (see Table 1). The absorption band $\lambda_{2}$ is attributed to the transition in $\alpha, \beta$ unsaturation on the antipyrine ring. $\lambda_{3}$ is ascribed to the transition of the aromatic ring and $\lambda_{4}$ corresponds to the transition in the amide carbonyl moiety [15]. In antipyrine, $\lambda_{1}$ is the $\mathrm{n} \rightarrow \sigma^{*}$ transition. Table 1 gives a summary of the absorption wavelengths of the four antipyrines.
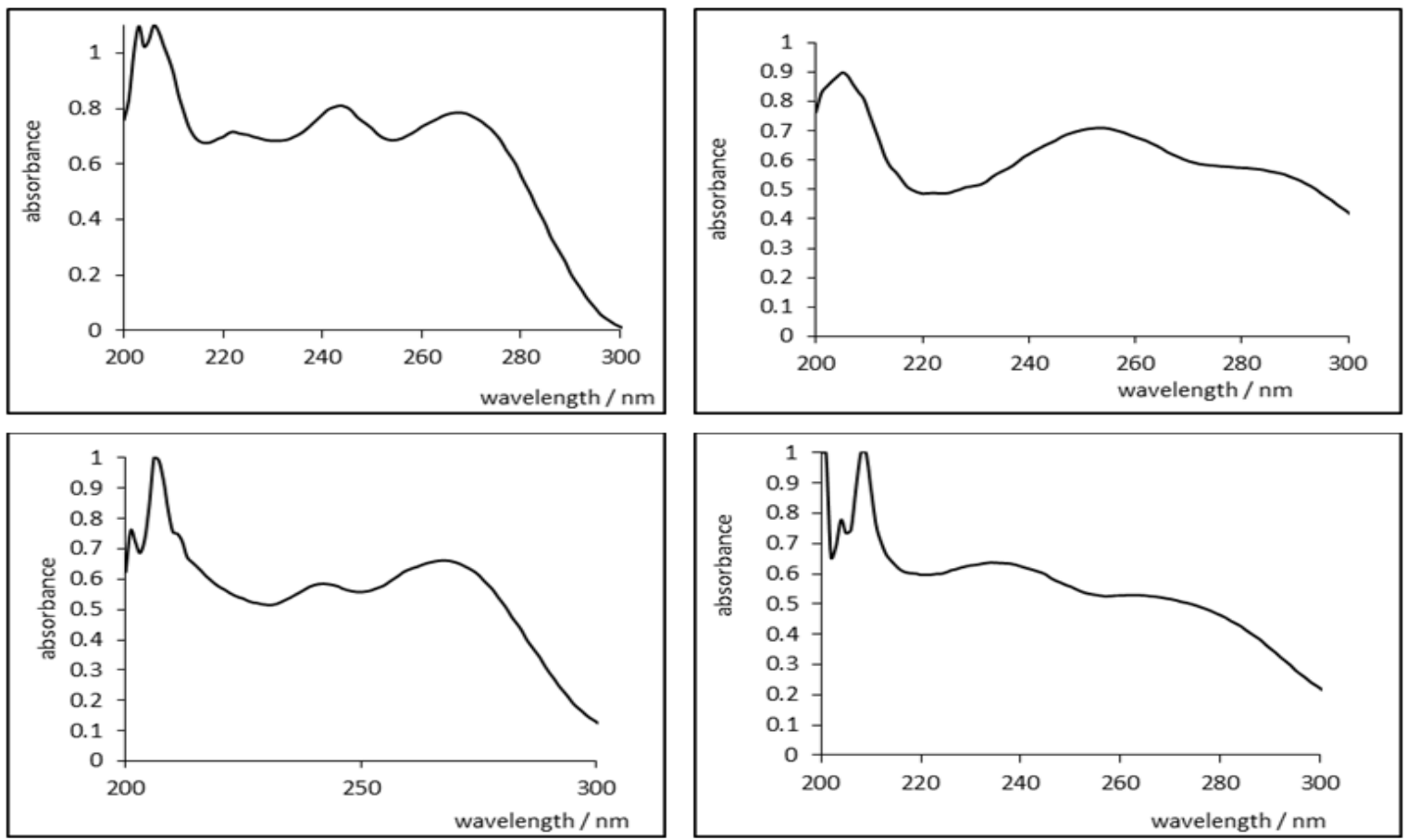

Figure 1. UV spectra of antipyrine (top left), 4-aminoantipyrine (top right), methylaminoantipyrine (bottom left) and metamizole (bottom right). See also Table 1

Table 1. Structure and wavelengths of the bands in the UV-VIS spectrum

\begin{tabular}{|c|c|c|c|c|c|}
\hline Substance & Structure & $\lambda_{1}[\mathrm{~nm}]$ & $\lambda_{2}[\mathrm{~nm}]$ & $\lambda_{3}[\mathrm{~nm}]$ & $\lambda_{4}[\mathrm{~nm}]$ \\
\hline antipyrine & & 204 & 220 & 241 & 263 \\
\hline 4-aminoantipyrine & & 202 & 209 & 248 & 281 \\
\hline methylaminoantipyrine & & 201 & 206 & 240 & 268 \\
\hline metamizole & & 208 & 220 & 230 & 263 \\
\hline
\end{tabular}




\subsection{Mass Spectrometric Characterisation of Antipyrine, 4-aminoantipyrine, 4-methylaminoantipyrine and Metamizole}

Aminoantipyrine-like molecules differ only by the substituents at the carbon atom in position 4 on the pyrazolone moiety. Metamizole presents a methylamino$\mathrm{N}$-methanesulfonate group that dissociates by hydrolysing, forming methylaminoantipyrine and dimethylaminoantipyrine [16]. The hydrolytic and pharmacokinetics of metamizole can be mechanistically characterised as a retro-Mannich reaction. The resulting methylantipyrine has $85 \%$ bioavailability after oral administration and takes $1-2 \mathrm{~h}$ to achieve maximal systemic concentrations [17].
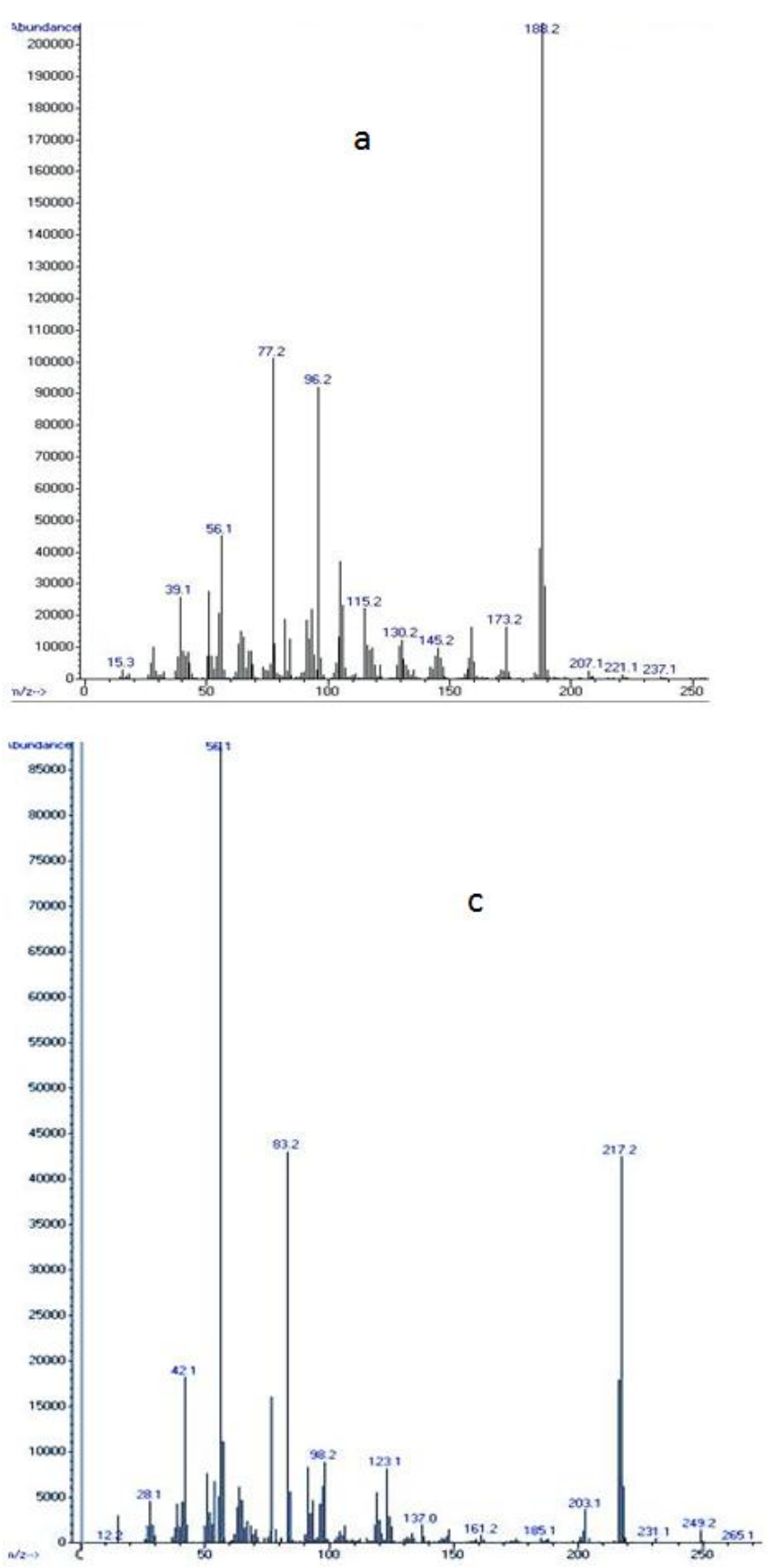

In addition, metamizole undergoes thermal decomposition by cleavage of the sulfonate and methanesulfonate groups, forming dimethylaminopyrine and methylaminopyrine [16,19]. Isaacs et al. [16] could identify metamizole without decomposition by electrospray-MS and ${ }^{1} \mathrm{H}-\mathrm{NMR}$ in DMSO- $\mathrm{d}_{6}$ as the solvent.

In this article, however, we have not considered these subtleties. Figure 2 shows the electron impact EI-mass spectrum of antipyrine (Figure 2 a), 4-aminoantipyrine (Figure 2 b), methylaminoantipyrine (Figure $2 \mathrm{c}$ ) and metamizole (Figure $2 \mathrm{~d}$ ). All substances were dissolved in methanol and were injected into the GC-MS (and not directly into the mass spectrometer). Therefore, the substances, especially metamizole, could have undergone thermal decomposition.
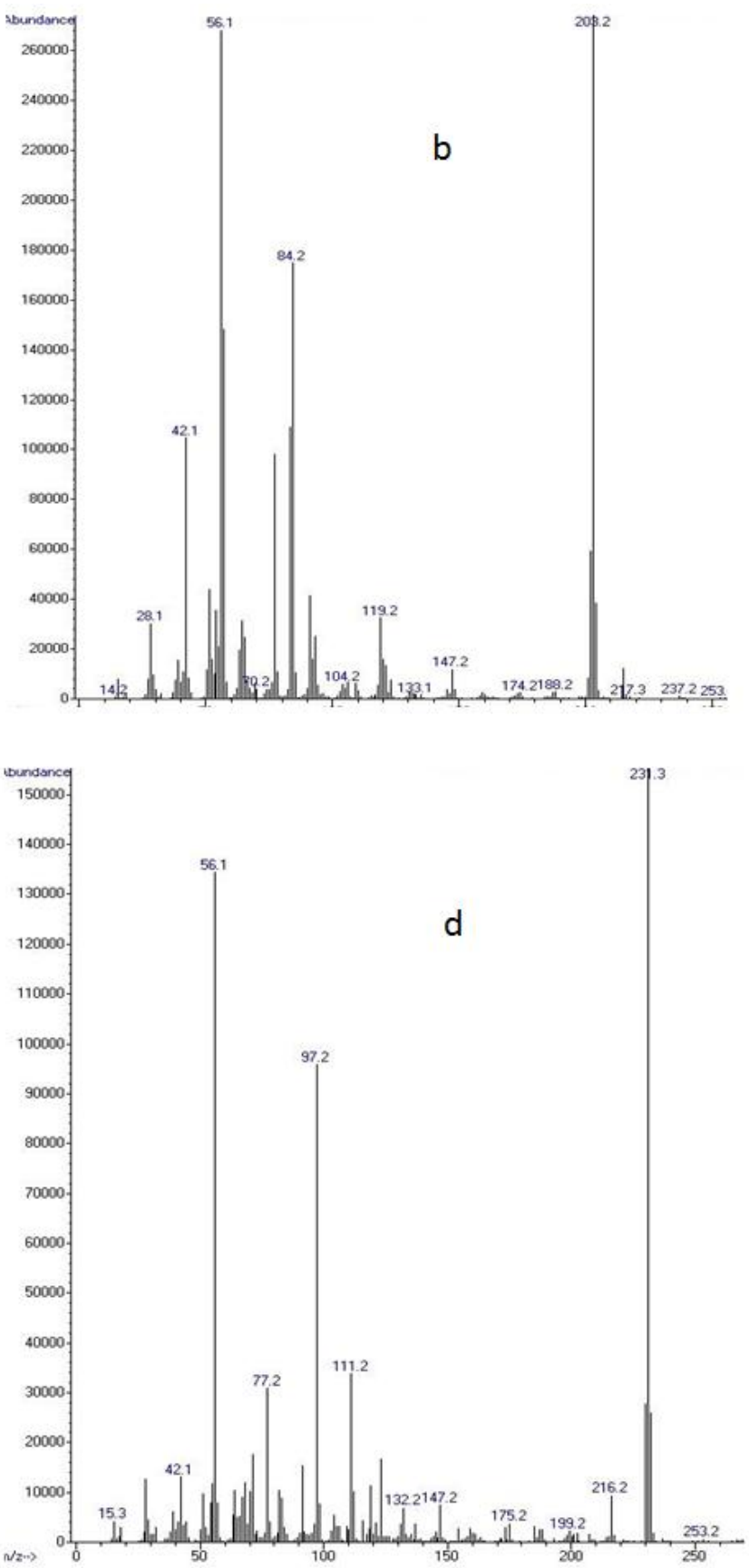

Figure 2. EI-mass spectra. a) antipyrine;b): 4-aminoantipyrine; c) methylaminoantipyrine; d) metamizole (dimethylaminoantipyrine) 


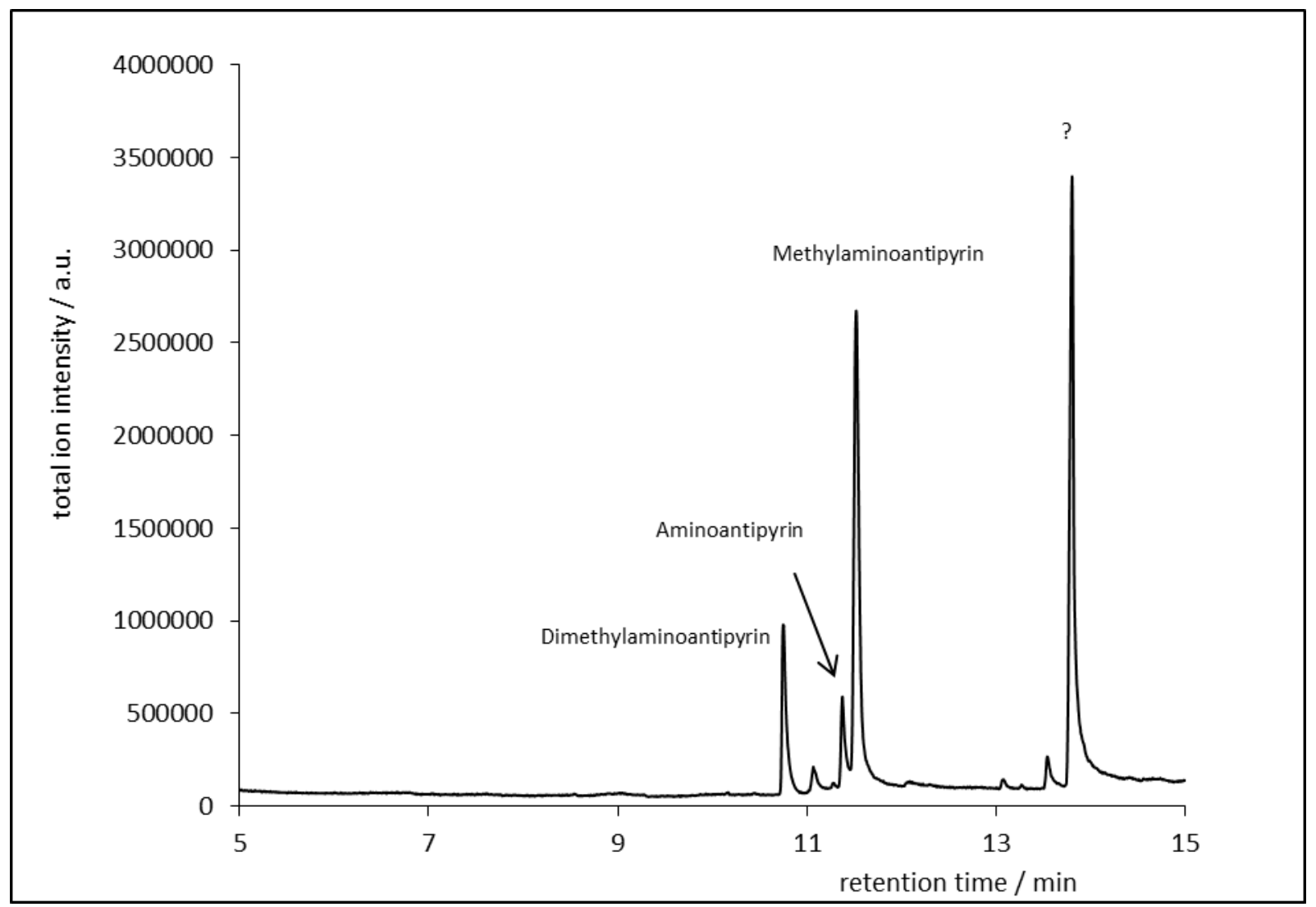

Figure 3. GC-MS of a mixture of aminoantipyrine, methylaminoantipyrine and metamizole. The substance at about 14 min could not be identified

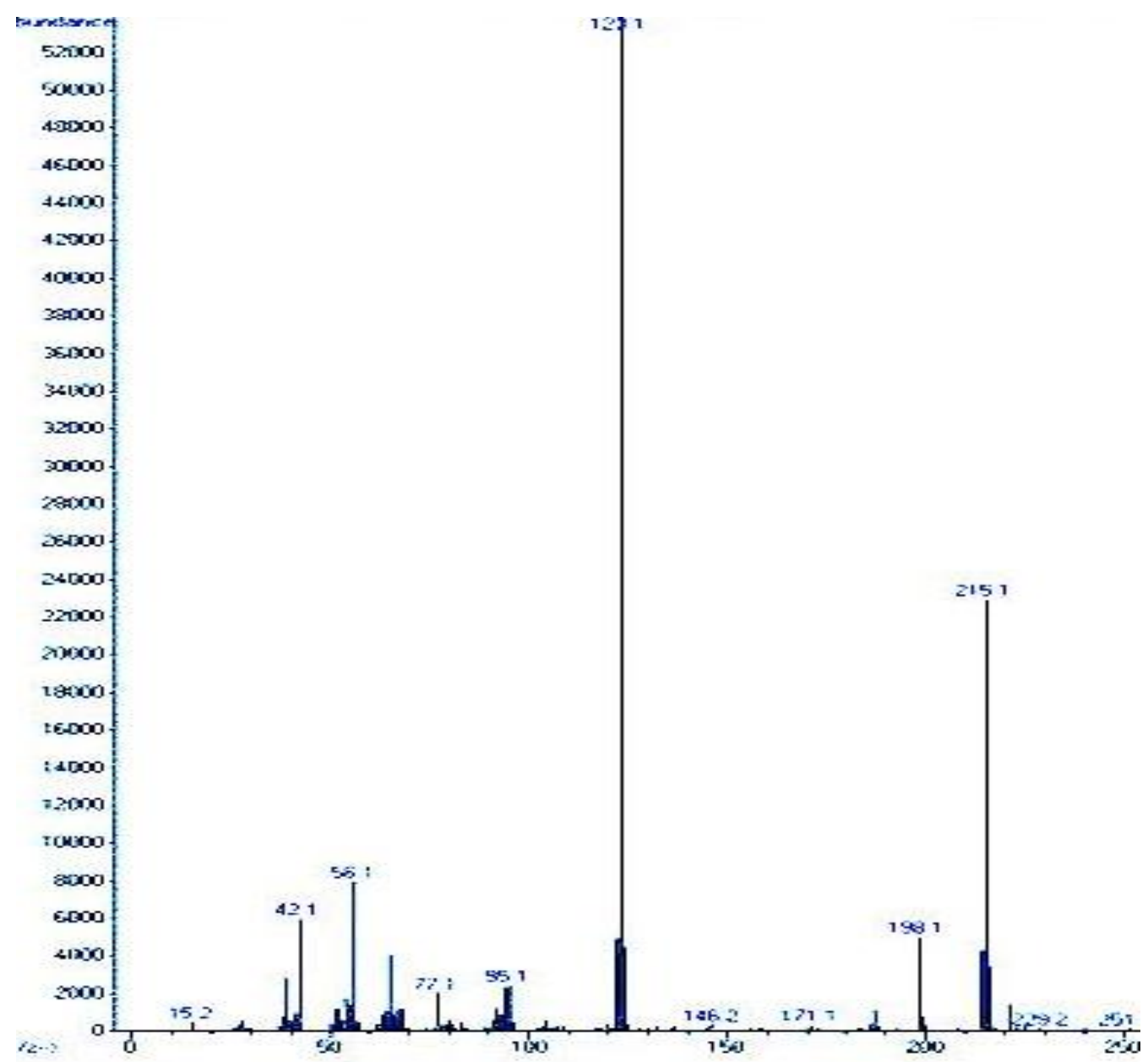

Figure 4. EI-MS of the substance at the 14-min retention time 
Injecting a mixture of aminoantipyrine, methylaminoantipyrine and metamizole into the GC-MS resulted in dimethylaminoantipyrine and another substance with a high yield that could not be unequivocally identified (see the question mark in Figure 3). The mass spectrum of this substance is quite similar to that of methylaminoantipyrine but the fragment distribution is different (Figure 4).

The concentration dependence of metamizole (measured by the thermal decomposition product dimethylaminoantipyrine at $10.6 \mathrm{~min}$ ) is shown in Figure 5 and Figure 6.

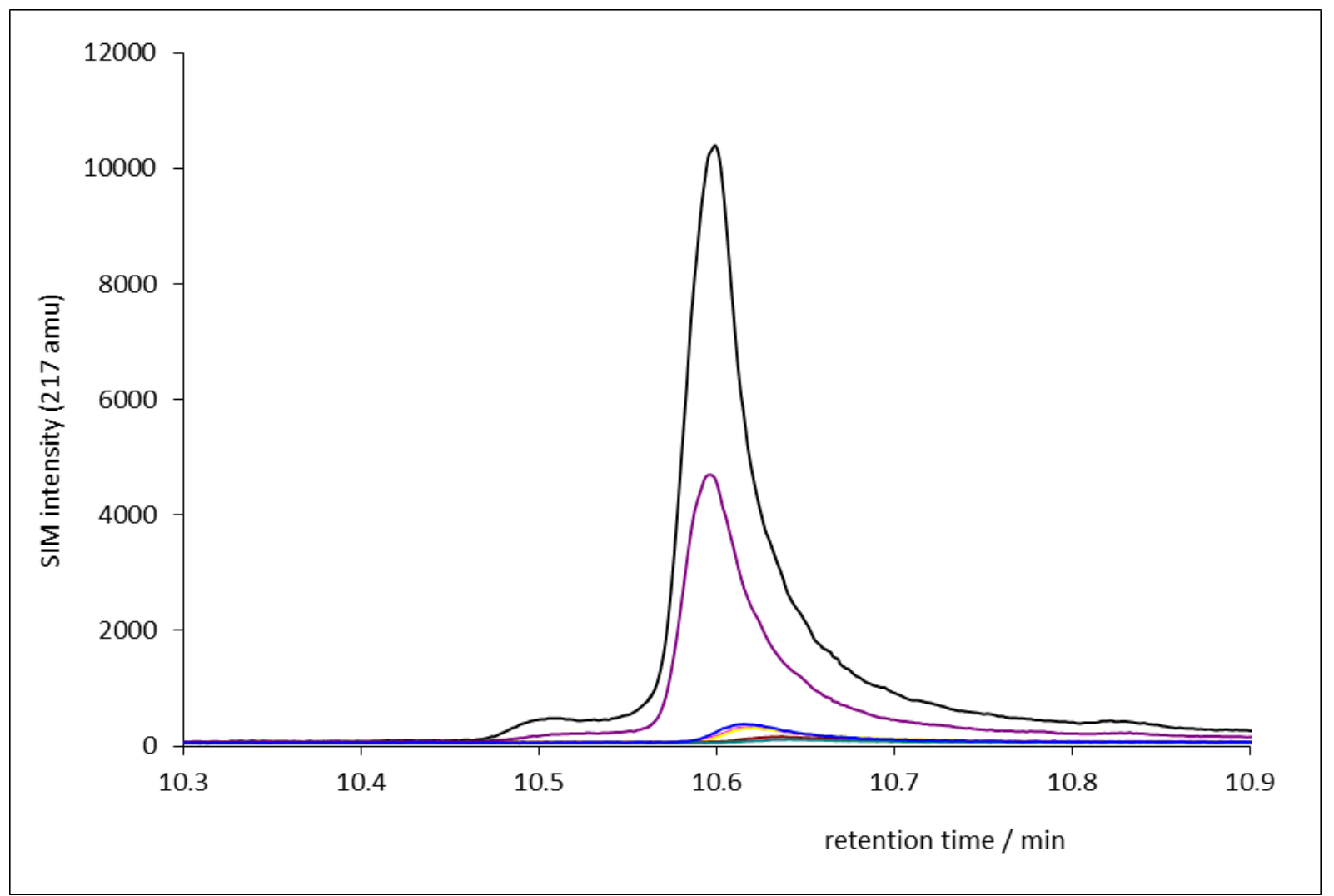

Figure 5. Concentration dependence of dimethylaminoantipyrine, the thermal decomposition product of metamizole, in the range of $55 \mu$ mol/L$500 \mu \mathrm{mol} / \mathrm{L}$. Insert: $55 \mu \mathrm{mol} / \mathrm{L}-100 \mu \mathrm{mol} / \mathrm{L}$

In the SIM mode the LOD is about fifty times lower than in the scan mode (selected mass: $231 \mathrm{amu}$ ).

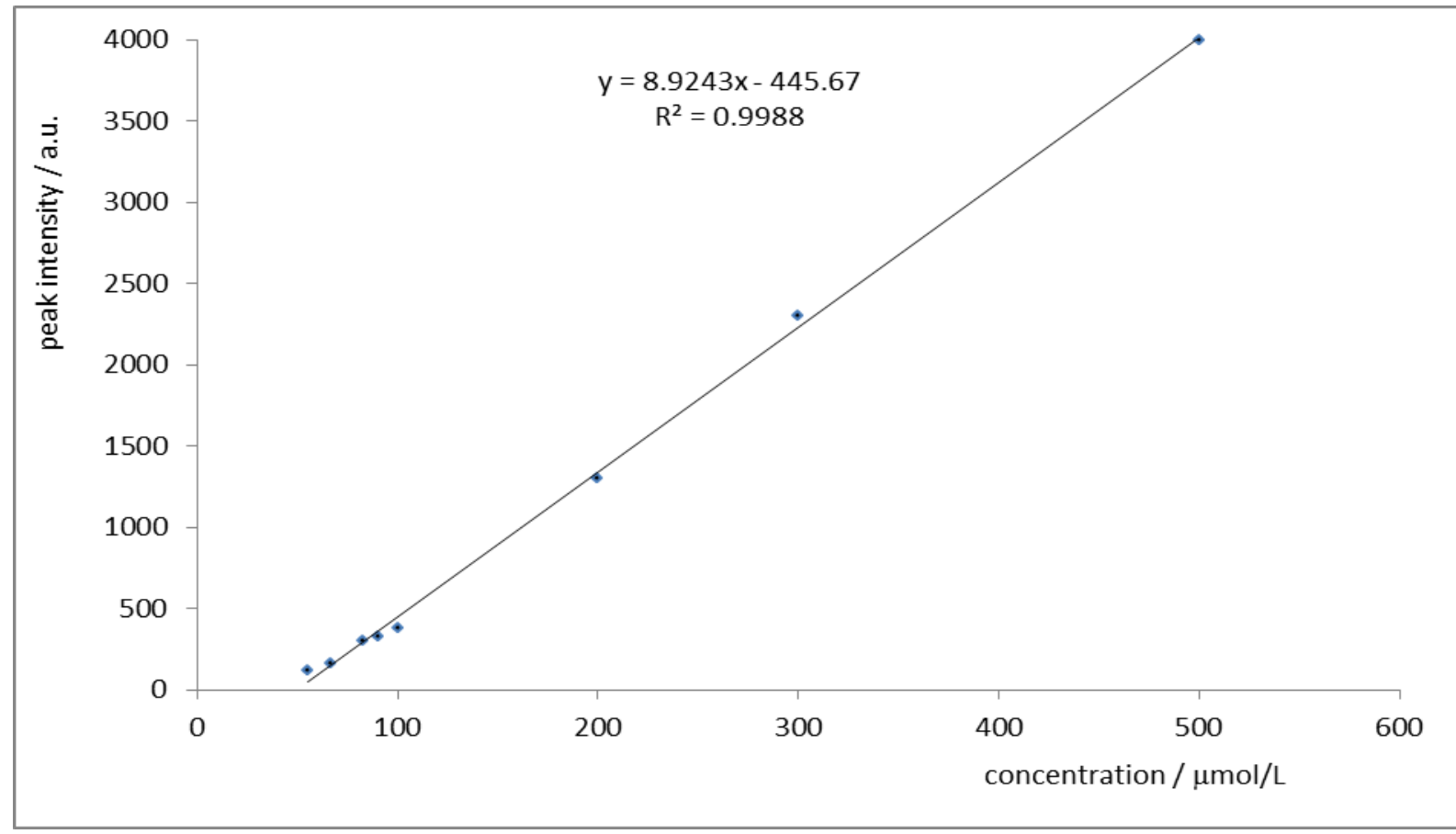

Figure 6. Concentration dependence of dimethylaminoantipyrine. The curve shows a linear dependence between 55 and $500 \mu$ mol/L

The calculated LOD is $50 \mu \mathrm{mol} / \mathrm{L} * 1 \mu \mathrm{L}=50 \mathrm{pmol}$ or $15.6 \mathrm{ng}$ (with molecular weight of metamizole $=313 \mathrm{~g} / \mathrm{mol}$ ). 
Table 2. Masses and structures of the main fragments of the four antipyrine derivatives [18]

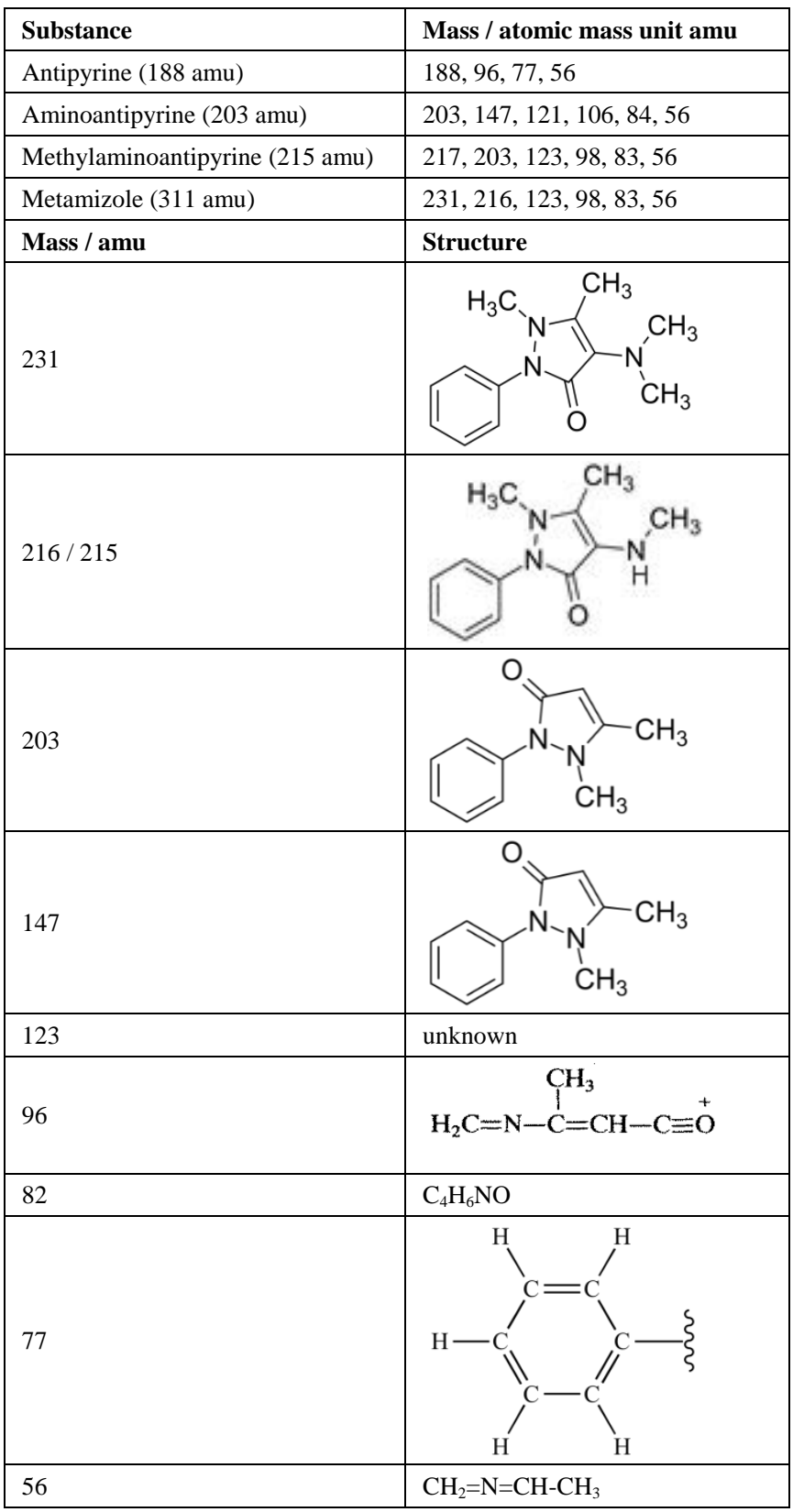

\subsection{Electrochemical Characterisation via Cyclic Voltammetry}

Several electrochemical investigations of metamizole have been carried out with different types of electrodes, including glassy carbon electrodes [20] and carbon paste electrodes [21]. Metal electrodes as platinum were used by Basaez et al. [22] while Munoz [23] used gold electrodes. Dadamos et al. [19] modified a carbon paste electrode with nickeldoped potassium strontium niobate. This electrode exhibits reversible behaviour, high conductivity and durability. In addition, the electrode promotes the oxidation of dipyrone by first oxidising niobium(IV) to niobium(V) at the electrode surface. The niobium(V) then undergoes a reduction by dipyrone back to niobium(IV). Baranowska et al. [24] used a hanging mercury drop and a graphite electrode for differential pulse voltammetry for the simultaneous detection of different drugs (paracetamol, furosemide, dipyrone, dexamethasone, and cefazolin) in spiked urine samples.

We used different SPEs to determine the best current response and electrochemical resolution. The scanning electron microscope image (SEM) of the Au SPE used is shown in Figure 7. Figure 8 shows the best result with an Au SPE.

At about $0.4 \mathrm{~V}$ and $0.6 \mathrm{~V}$, the enamine moiety $(-\mathrm{C}=\mathrm{C}-\mathrm{N}-$, see the circle in the structure)

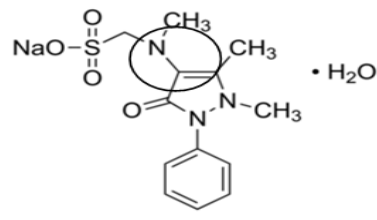

oxidizes and forms an iminium radical cation. In the reversed scan, a small cathodic peak can be observed at $0.25 \mathrm{~V}$. The voltage difference between the anodic and cathodic peak is about $150 \mathrm{mV}$. Therefore, the redox reaction is quasi-reversible.

After Bacic et al. [15], the oxidized metamizole can subsequently react (dimerize) at $0.4 \mathrm{~V}$ (EC mechanism). This was demonstrated when the reverse scan was started at different voltages. When it was started at $0.5 \mathrm{~V}$, the oxidation peak is more pronounced (see dotted line in Figure 9).

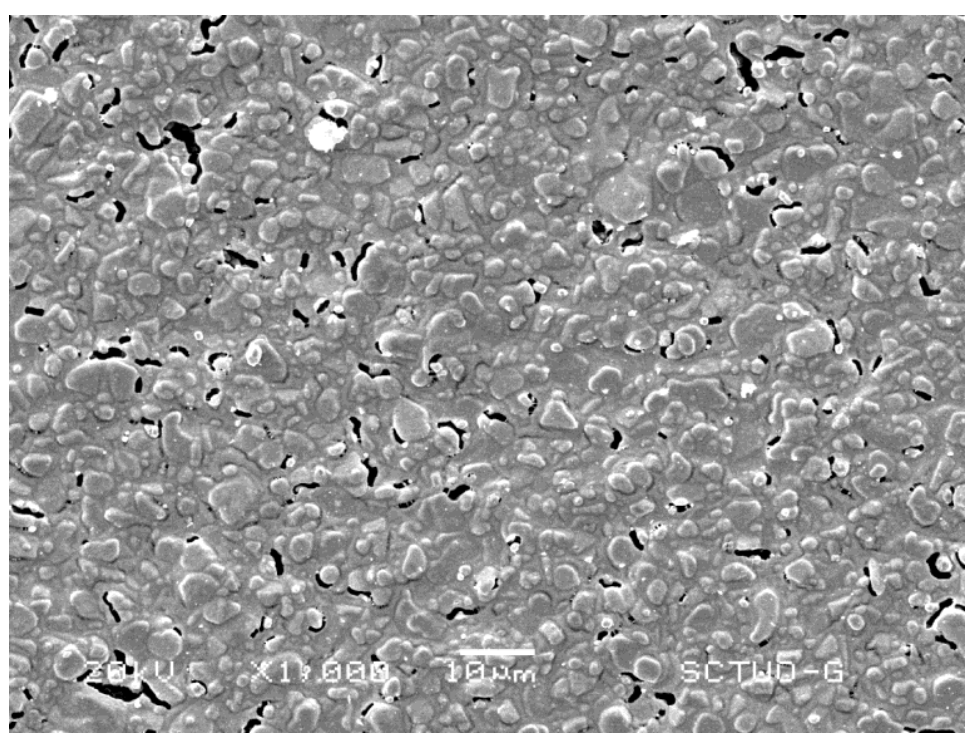

Figure 7. SEM of the Au SPE (kindly from DropSens) 


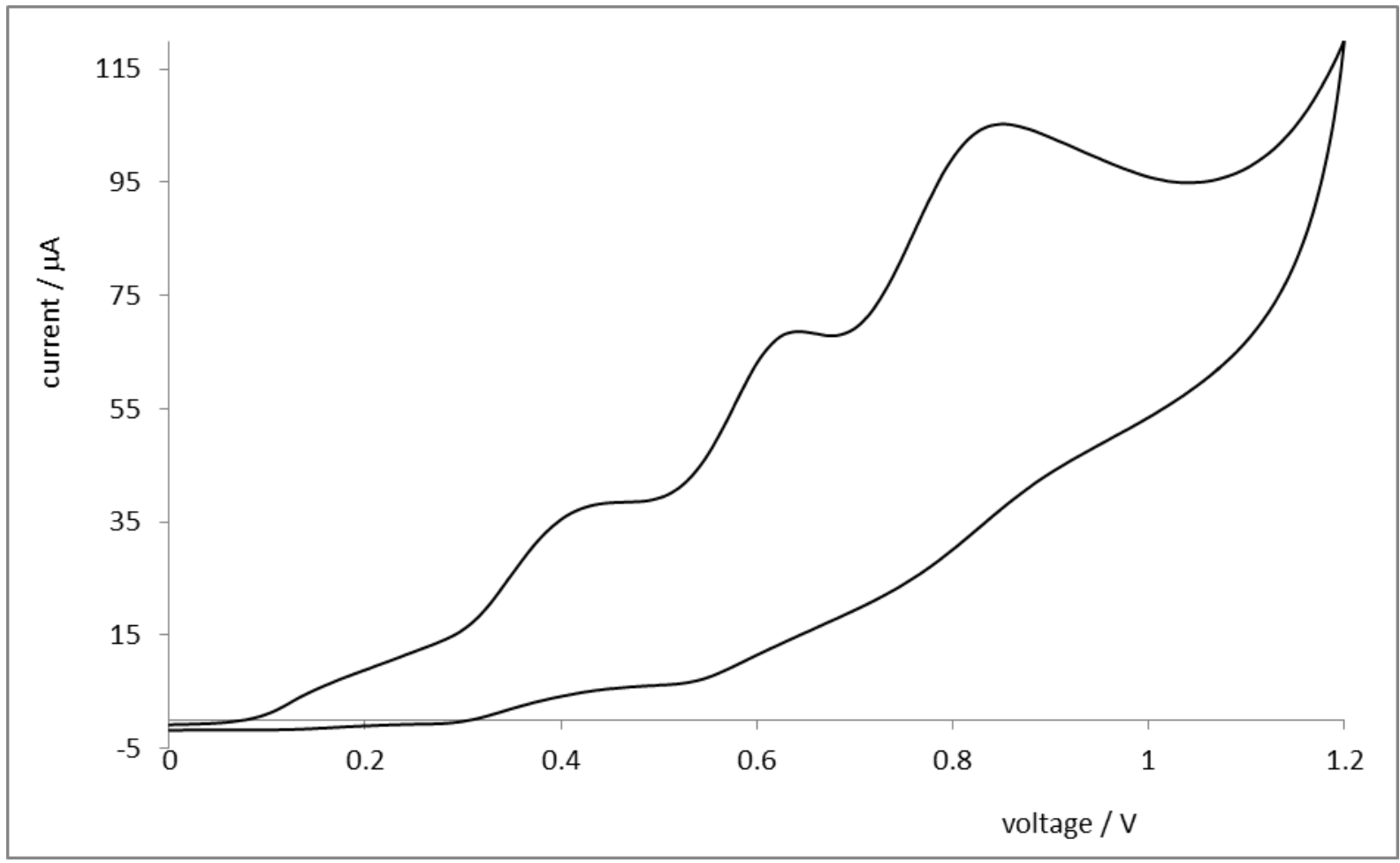

Figure 8. Cyclic voltammogram (CV) of metamizole with gold as the working electrode

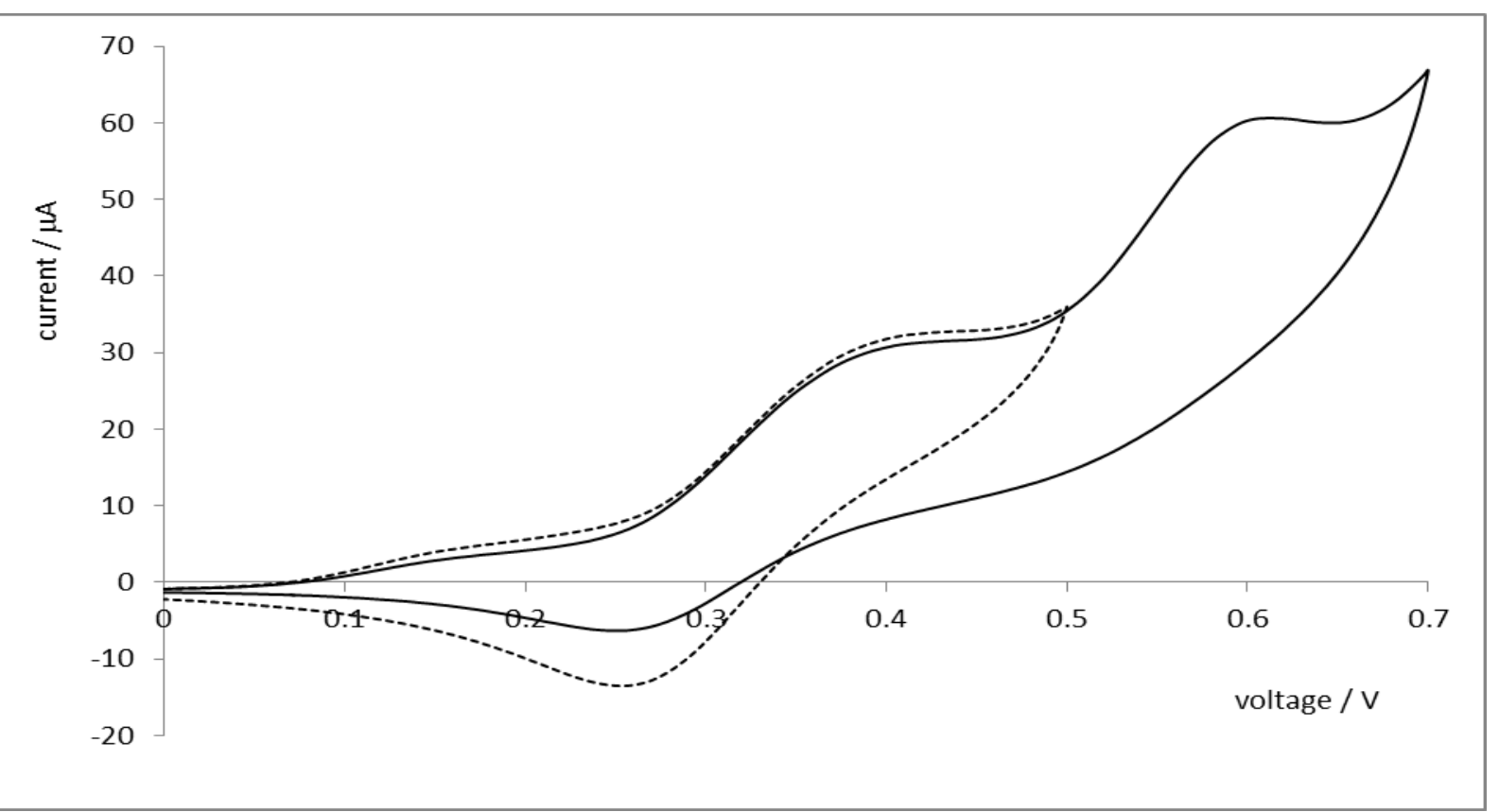

Figure 9. $\mathrm{CV}$ of metamizole with different voltage ranges

The oxidation process at $0.8 \mathrm{~V}$ is common to all antipyrines. Therefore, the most plausible oxidation possibility is the nitrogen adjacent to the phenyl ring [15].

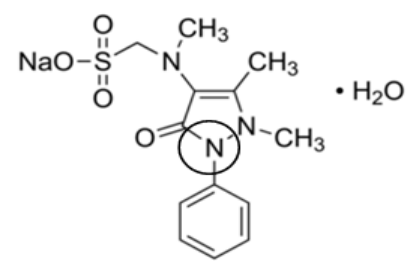

Figure 10 shows the CVs of antipyrine and the three derivatives with a single-walled carbon nanotube working electrode (note the slight voltage shift compared to the working electrode used above). 


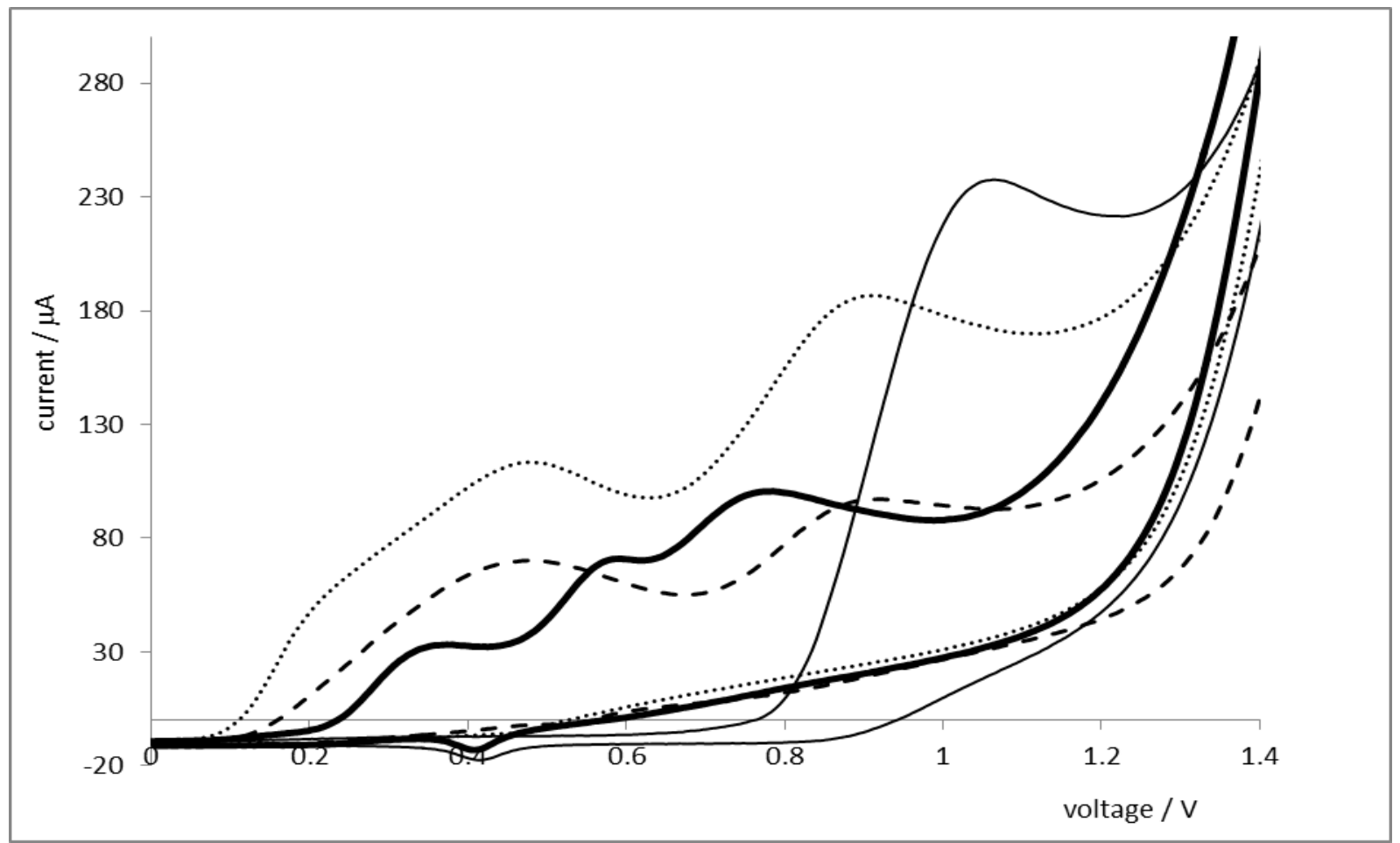

Figure 10. CVs of the four antipyrine derivates at $\mathrm{pH}$ 10. Thick line: metamizole; thin line: antipyrine; dotted line: 4-aminoantipyrine; dashed line: methylaminoantipyrine

\subsection{Electrogenerated Chemiluminescence (ECL)}

Since the 1960s, the ECL technique has become increasingly attractive in analytical chemistry. ECL involves the generation of an excited state of the commonly used and intensively investigated tris(2,2'bipyridyl)ruthenium (II) $\left[\mathrm{Ru}(\mathrm{bpy})_{3}\right]^{2+}$ on an electrode surface. First, the $\left[\operatorname{Ru}(\mathrm{bpy})_{3}\right]^{2+}$ is oxidized; then, it undergoes an electron-transfer reaction with a co-reactant. During the latter process, an excited state is created that subsequently decays and emits light. Reviews of ECL are given by Miao [25], Kapturwicz [26], Hercules [27], Richter [28], Parveen [29] and Bard [30].

The ECL system used is a combination of $\left[\mathrm{Ru}(\mathrm{bpy})_{3}\right]^{2+}$ and proline (as co-reactant), which produces one of the most intense ECLs [14]. In addition, this system has excellent water solubility and is less toxic than tripropylamine, one of the most common co-reactants in ECL studies. The ECL is quenched by adding metamizole. Quenching can be used to quantitatively determine metamizole. Figure 11 shows the ECL quenching at three different metamizole concentrations $(1 \mathrm{mmol} / \mathrm{L}, 0.5 \mathrm{mmol} / \mathrm{L}$ and $0.1 \mathrm{mmol} / \mathrm{L})$.

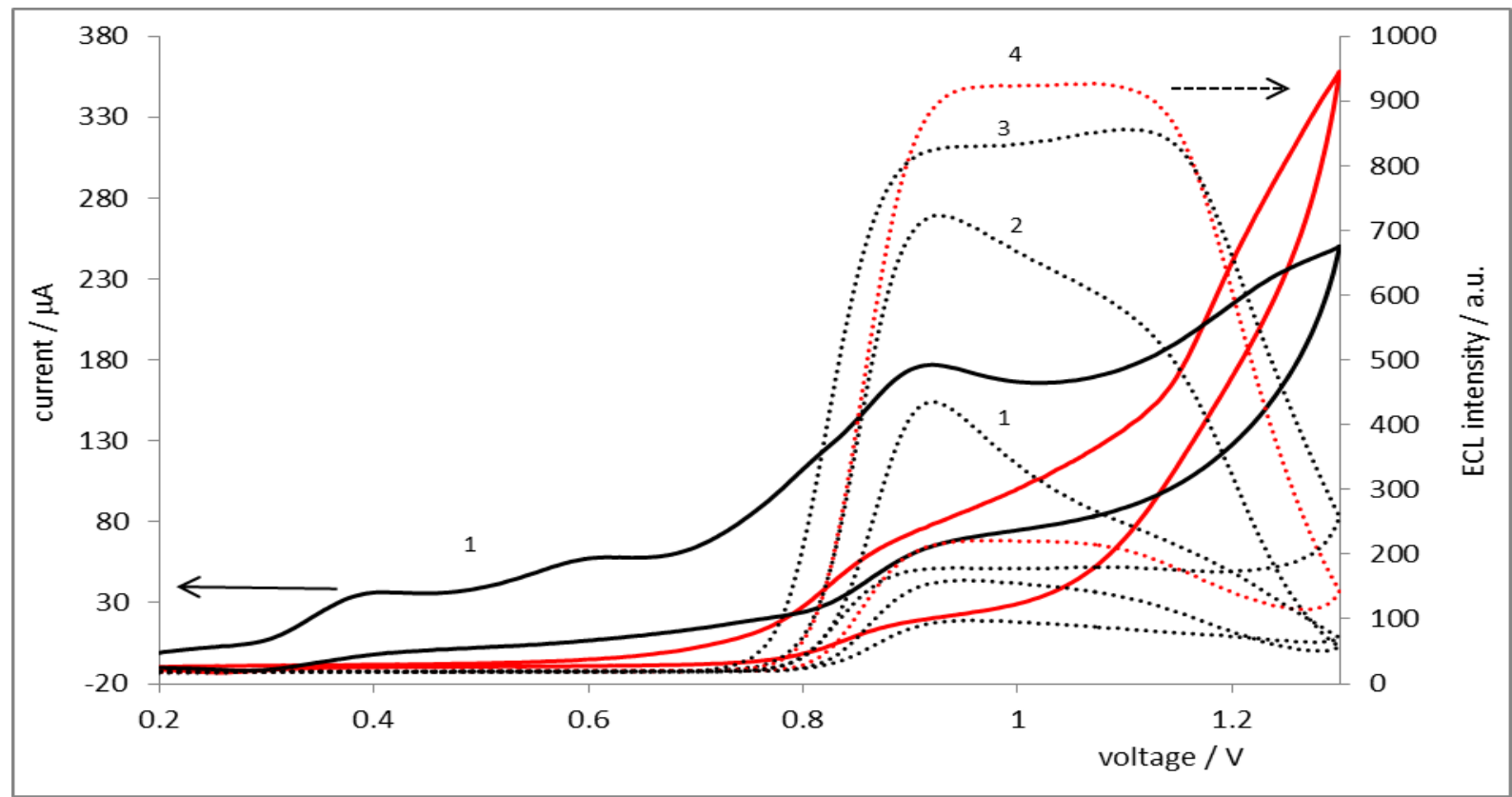

Figure 11. Cyclic voltammograms and electrogenerates curves. Solid lines: cyclic voltammograms; dotted lines: ECL of $\left[\mathrm{Ru}(\mathrm{bpy})_{3}\right]^{2+} /$ proline with (concentrations from $1 \mathrm{mmol}, 0.5 \mathrm{mmol}$ and $0.1 \mathrm{mmol}(1 \rightarrow 3)$ ) and without $(4)$ metamizole. Working electrode: Au 220 AT 


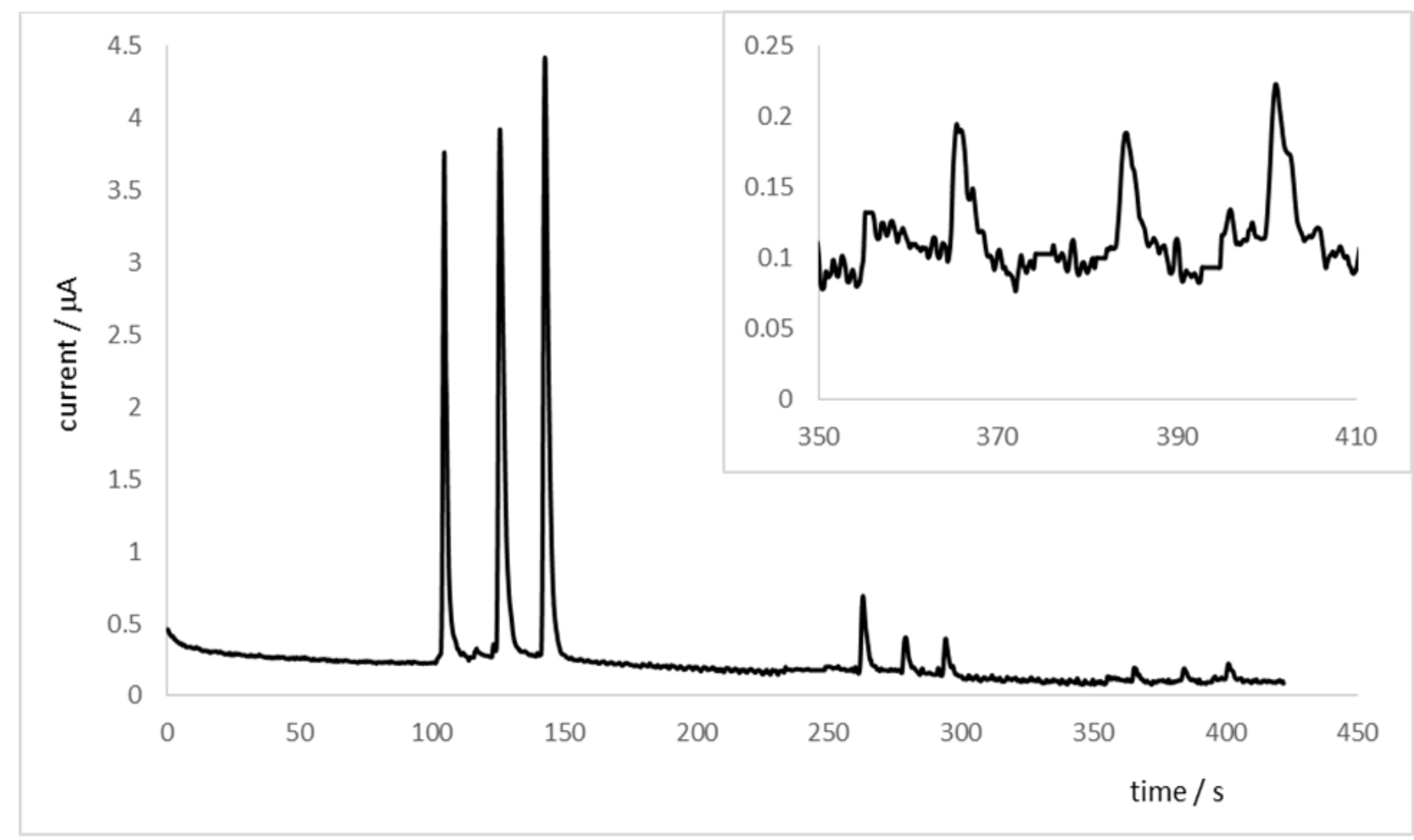

Figure 12. Amperometric detection of metamizole at $\mathrm{pH}$ 10. Injection volume: $10 \mu \mathrm{L}$. Three different concentrations $-1 \mathrm{mmol} / \mathrm{L}, 90 \mu \mathrm{mol} / \mathrm{L}$ and $8 \mu \mathrm{mol} / \mathrm{L}$-injected three times. $\mathrm{LOD}=8 * 10^{-11} \mathrm{~mol}=25 \mathrm{ng}$

\subsection{Amperometric Detection}

A simple, rapid and low-cost method to quantify metamizole is amperometric detection (AM). In association with flow injection analysis (FIA), AM provides a fast analysis [23]. Perez-Ruiz [31] used a glassy carbon electrode for amperometric detection and measured the LOD as a function of flow rate and coil length between 1 and $10 \mu \mathrm{g} / \mathrm{mL}$.

Burcinova et al. [32] determined antipyrine and 4-aminoantipyrine in urine with HPLC and amperometry detection (carbon fibre array as working electrode). The authors concluded that photometric detection is more sensitive than amperometric detection. However, photometric detection requires pre-concentration of urine samples by extraction.

In our own AM measurements, we tested two electrodes: SWCNT SPE and Au SPE. No difference was observed between these electrodes but practicability was better for the latter. This was ascribed to the better cleaning procedure: the gold electrode is rinsed with concentrated nitric acid and then with distilled water. The electrode was installed inside the electrochemical HPLC cell and the injection of the aqueous metamizole solution $(\mathrm{pH} \mathrm{10)}$ was done via a Rheodyne valve (injection volume $10 \mu \mathrm{L}$ ). The pumping speed was $2 \mathrm{~mL} / \mathrm{min}$. The current was recorded as $0.25 \mathrm{~V}$ at three different metamizole concentrations $(1 \mathrm{mmol} / \mathrm{L}$, $90 \mu \mathrm{mol} / \mathrm{L}$ and $8 \mu \mathrm{mol} / \mathrm{L})$. All solutions were injected three times. Figure 12 shows the amperometric curves. The LOD is about $5 \mu \mathrm{mol} / \mathrm{L}$ (signal to noise ratio $3: 1$ ).

\section{Discussion}

This paper has described mass spectrometry and three (spectro)electrochemical methods for identifying metamizole: CV, ECL and AM. We have shown that these methods have different LODs and that the ECL signal has the disadvantage of having poor reproducibility. The electrodes used had to be cleaned before each measurement to assure that the electrode had no ageing effect through passivation.

Table 3 compares the LODs and gives a final appraisal of the methods used.

Table 3. Summary of the methods used

\begin{tabular}{|c|c|c|}
\hline Method & LOD & Estimation \\
\hline mass spectrometry & $\begin{array}{l}50 \mu \mathrm{g} / \mathrm{L}(1 \mu \mathrm{L} \text { injection }) \text { in the scan } \\
\text { mode and } 1 \mu \mathrm{g} / \mathrm{L} \text { in the SIM mode. }\end{array}$ & $\begin{array}{l}\text { Expensive, low limit of detection (especially in the SIM } \\
\text { mode), convenient method for simultaneous detection of a } \\
\text { wide range of substances. } \\
\text { Disadvantage: metamizole decomposes by thermal heating. }\end{array}$ \\
\hline $\mathrm{CV}$ & no LOD measured & Easy to use for identifying the electrochemical reactions. \\
\hline $\mathrm{ECL}$ & $100 \mu \mathrm{g} / \mathrm{L}(10 \mu \mathrm{L}$ onto the electrode $)$ & $\begin{array}{l}\text { Information about quenching the chemiluminescence of } \\
{\left[\mathrm{Ru}(\mathrm{bpy})_{3}\right]^{2+} / \text { proline; comparably low reproducibility. }}\end{array}$ \\
\hline AM & $5 \mu \mathrm{g} / \mathrm{L}(10 \mu \mathrm{L}$ injection $)$ & Easy to use, appropriate method in combination with HPLC. \\
\hline
\end{tabular}




\section{Acknowledgements}

A. H. thanks the Vector foundation, the Fonds der Chemischen Industrie and the University of Ludwigsburg for financial support.

\section{References}

[1] Kümmerer, K., Drugs in the environment: emission of drugs, diagnostic aids and disinfectants into wastewater and surface water by hospitals in relation to other sources - a review, Chemosphere, 45, 957-969, 2001.

[2] Feldmann, D.F., Zuehlke, S., Heberer, T., Occurrence, fate and assessment of polar metamizole (dipyrone) residues in hospital and municipal wastewater, Chemosphere, 71, 1754-1764, 2008.

[3] Thomas, K.V., Dye, C., Schlabach, M., Langford, K.H., Source to sink tracking of selected human pharmaceuticals from two Oslo city hospitals and a wastewater treatment works, J. Environ. Monitor. 9, 1410-1418, 2007.

[4] Gomez, M.J., Petrovic, M., Alba, A.R.F., Barceló, D., Determination of pharmaceuticals of various therapeutica classes by solid-phase extraction and liquid-chromatography-tandem mass spectrometry analysis in hospital effluent wastewaters, $J$. Chromatogr. A 1114, 224-233, 2006.

[5] Verlicchi, P., Al Aukidy, A., Galletti, A., Petrovic, M., Barceló, D., Hospital effluent: Investigation of the concentration and distribution of pharmaceuticals and environmental risk assessment, Sci. of Total Environ., 430, 109-118, 2012.

[6] Bacil, R.P., Buoro, R.M., da Silva, R.P., Medinas, D.B., Lima, A.W.O., Serrano, S.H.P., Mechanism of Electro-Oxidation of Metamizole using Cyclic Voltammetry at a Glassy Carbon Electrode, ECS Transactions, 43(1), 251-258, 2012.

[7] Moldovan, Z., Occurrences of pharmaceutical and personal care products as micropollutants in rivers from Romania, Chemosphere, 64, 1808-1817, 2006.

[8] Gyenge-Szabo, Z., Szoboszlai, N., Frifyes, D., Zaray, G., Mihucz, V.G., Monitoring of four dipyrone metabolites in communal wastewater by solid phase extraction liquid chromatography electrospray ionization quadrupole time-of-flight mass spectrometry, J. Pharmaceut. and Biomed. Anal., 90, 58-63, 2014.

[9] Zhang, C., Zhang, L., Cao, S., Jiang, Z., Wu, H., Yan, M., Zhang, X., Jiang, S., Xue, F., Simultaneous determination of residues of dipyrone metabolites in goat tissue by hydrophilic interaction liquid chromatography tandem mass spectrometry, Food Chem. 196, 83-89, 2016

[10] Anatas, P.T., Warner, J.C., Green Chemistry: Theory and Practice, Oxford University Press, New York, p. 30, 1998.

[11] Hjereresen, D. L., Schutt, D.L., Boese, J.M., Green Chemistry and Education, J. Chem. Educ. 77 (12), 1543-1547, 2000.

[12] Hill, J., Kumar, D.D., Verma, R.K., Challenges for Chemical Education: Engaging with Green Chemistry and Environmental Sustainability, J. Chem. Educ. 86 (1), 24-31, 2013.

[13] Stearns, C., Environmental Chemistry in the High School Curriculum, J. Chem. Educ. 65 (3), 232-234, 1988.

[14] Habekost, A. Investigations of some reliable electrochemiluminescence systems on the basis of tris(bipyridyl)ruthenium(II) for HPLC analysis, World J. Chem. Educ. 4, 13-20, 2016.
[15] Bacil, R.P., Buoro, R.M., Campos, O.S., Ramos, M.A., Sanz, C.G., Serrano, S.H.P., Electrochemical behavior of dipyrone (metamizol) and others pyrazolones, Electrochim. Act. 273, 358-366, 2018.

[16] Isaacs, R.C.A., Harper, M.M., Miller, E.C., Analytical challenge in the confirmative identification of dipyrone as an adulterant in illicit drug sample, Forensic Sci. Int. 270, 185-192, 2017.

[17] Rogosch, T., Sinning, C., Podlewski, A., Watzer, B., Schlosburg, J., Lichtman, A.H., Cascio, M.G., Bisogno, T., Di Marzo, V., Nüsing, R., Imming, P., Novel bioactive metabolites of dipyrone (metamizol), Bioorg. \& Med. Chem., 20, 101-107, 2012.

[18] Zitz, E., Spiteller, G., Location of Functional Groups in Antipyrine Metabolites by Mass Spectrometry, Biomed. Mass. Spectro., 4, 155-158, 1977.

[19] Dadamos, T.R.L., Freitas, B.H., Genova, D.H.M., Espirito-Santo, R.D., Gonzales, E.R.P., Lanfredi, S., Teixeira, M.F.S., Electrochemical characterization of the paste carbon modified electrode with $\mathrm{KSr}_{2} \mathrm{Ni}_{0.75} \mathrm{O}_{15-\delta}$ solid in catalytic oxidation of the dipyrone, Sens. and Act. B, 169, 267-273, 2012.

[20] Bacil, R.P., Buoro, R.M., da Silva, R.P., Medinas, D.B., Lima, A.W.G., Serrano, S.H.P., Mechanism of electro-oxidation of metamizol using cyclic voltammetry at a glassy carbon electrode, ECS Trans. Electrochem. Soc. 43, 251-258, 2012.

[21] Marcolino-Junior, L.H., Bergamini, M.F., Teixeira,, M.F.S., Cavalheiro, E.T.G., Fatibello-Filho, O., Flow injection amperometric determination of dipyrone in pharmaceutical formulations using a carbon paste electrode, Farmaco, 58, 9991004, 2003.

[22] Basaez, L., Peric, I.M., Jara, P.A., Soto, C.A., Contreras, D.R., Aguirre, C., Vanysek, P., Electrochemical and electrophoretic study of sodium metamizol, J. Chil. Chem Soc. 53, 1572-1575, 2008.

[23] Munoz, R.A.A., Matos, R.C., Angnes, L, Amperometric Detection of Dipyrone in Pharmaceutical Formulations with a Flow Cell Containing Gold Electrodes from Recordable Compact Discs, $J$. Pharma. Sci., 90, 1972-1977, 2001.

[24] Baranowska, I., Markowski, P., Gerle, A., Baranowski, J., Determination of selected drugs in human urine by differential pulse voltammetry technique, Bioelectrochem. 73, 5-10, 2008.

[25] Miao, W., Choi, J.P., Bard, A. J., Electrogenerated Chemiluminescence 69: The Tris(2,2'-bipyridine)ruthenium(II), $\left(\mathrm{Ru}(\mathrm{bpy})_{3}{ }^{2+}\right) /$ Tri-n-propylamine (TPrA) System Revisited - A New Route Involving $\operatorname{TPrA}^{*+}$ Cation Radicals, J. Am. Chem. Soc., 124(48), 14478-14485, 2002.

[26] Kapturkiewicz, A., Electrogenerated chemiluminescence from the tris(2,2'-bipyridine)ruthenium(II) complex, Chem. Phys. Lett. 236 389-394, 1995.

[27] Hercules, D.M., Lytle, F.E., Chemiluminescence from reduction reactions, J. Am. Chem. Soc., 88, 4795-4796, 1966.

[28] Richter, M.M., Electrochemiluminescence (ECL), Chem. Rev. 104 3003-3036, 2004

[29] Parveen, S., Aslam, M.S., Hu, L., Xu, G., Electrogenerated Chemiluminescence. Protocols and Applications, Springer, Heidelberg, 2013.

[30] Bard, A.J. (Ed.), Electrogenerated Chemiluminescence, Marcel Dekker, New York, 2004.

[31] Perez-Ruiz, T., Lozano, C.M, Tomás V., Flow-injection determination of Novalgin using amperometric detection at a glassy carbon electrode, J. Pharm \& Biomed. Anal., 12 (9), 1109-1113, 1994.

[32] Burcinova, A., Tichy, M., Pacakova, V., Stulik, K., Application of amperometric detechtion to the high-performance liquid chromatographic determination of antipyrine and 4-aminoantipyrine in urine, J. Chromatogr. 455, 420-424, 1988. 